\title{
FOUR NEW SPECIES OF ERIOPHYOID MITES FROM BRAZIL (ACARINA, ERIOPHYOIDEA)
}

\author{
Carlos H.W. Flechtmann ${ }^{1}$
}

\begin{abstract}
Tegonotus tricarinatus n.sp., Floracarus claviger n.sp., Cosella callipodex $\mathbf{n}$.sp. and Aculus verrucosus n.sp., Acarina, Eriophyoidea, from Brazil are described and figured.

KEY WORDS. Eriophyoidea, Tegonotus, Floracarus, Cosella, Aculus, taxonomy
\end{abstract}

A survey on Brazilian plant feeding mites yielded four new species. These are herein described and figured. Measurements represent range, in micrometers. Those of setae are the longest able to be measured since setae are not always in horizontal position and often have very fine tips and break easily off.

\section{Tegonotus tricarinatus, n.sp.}

Fig. 1

Diagnose. T. tricarinatus is the third species described from a Leguminosae host and is distinctive in presenting the first tergite (dorsal annulus) twice as long as each of the remaining ones. In the general body outline it resembles T. marinalni (Keifer, 1939), except for the first long tergite. Its opisthosoma presents a longitudinal middorsal conspicuous ridge extending over tergites 2-11/13, as in $T$. marinalni, but is distinctive in having two longitudinal dorsolateral ridges extending from tergites 7-18 (4th tergite from rear), absent in T. marinalni. Dorsal shield setae are well ahead from shield rear margin and dorsal shield is smooth except for two short longitudinal lines in midfield, as in T. scoticus Roivainen, 1950, however, in this latter species the middorsal ridge is very moderate and extends over the entire opisthosoma.

Female. All measurements are reported in micrometers. Description from six specimens, 140-156 long, spindle shaped, 70-76 wide at the broadest point. Gnathosoma directed downward, 30-31 long; basal setae 5-8 long; antapical setae 4-5 long; chelicerae 19-25 long. Prodorsal shield (including frontal lobe) 51-57 long, 69-75 wide, frontal lobe 13-14 long; lightly punctate, punctuations barely visible. A short pair of admedian lines. Dorsal tubercles well ahead of shield rear margin, 25-29 apart, directing prodorsal setae upward and centrad; setae 5-9 long. Legs with all normal setae. Legs I, 32-34 long; trochanters 3 long; femora 8-10 long, femoral setae 8-11 long; genua 3-5 long, genual setae 18-21 long; tibiae 6-8 long,

1) Departamento de Zoologia, Universidade de São Paulo, ESALQ. 13418-900 Piracicaba, São Paulo, Brasil. Bolsista do CNPq. 


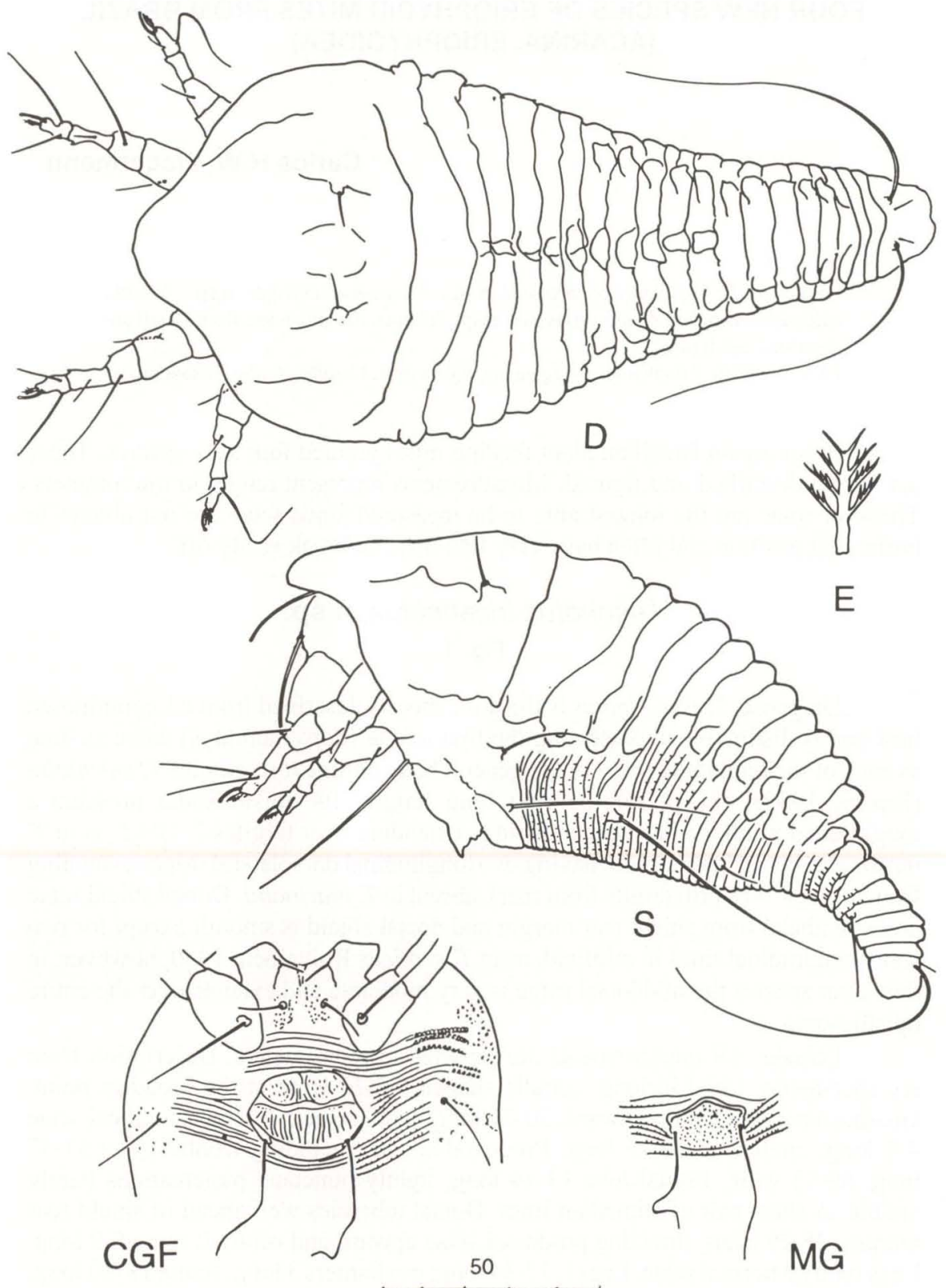

Fig. 1. Tegonotus tricarinatus, n.sp. CGF, D, E, S - female; MG - male. (CGF) Coxigenital region; (D) dorsal aspect; (E) empodium; (S) lateral aspect; (MG) male genitalia. 
tibial setae 4-5 long; tarsi 6-7 long, lateral setae 23-24 long, dorsal setae 18-22 long, mesal setae 4-5 long; solenidia 4-7 long, knobbed; empodia 4-6 long, 4-rayed. Legs II, 27-31 long; trochanters 3 long; femora 9-10 long, femoral setae 8-10 long; genua 3-4 long, genual setae 4-7 long; tibiae 5-6 long; tarsi 5-7 long, lateral setae 19-21 long, dorsal setae 4-6 long, mesal setae 3-5 long, solenidia 6-7 long, empodia 4-6 long, 4-rayed. Coxae - setae 1, 6-8 long, 10-12 apart; setae 2, 10-16 long, 9 apart; setae 3, 28-41 long, 23-24 apart. Coxigenital region with 6-7 annuli, smooth. Epigynium 20-21 wide, 16-17 wide, with 14-18 longitudinal lines on posterior half and two whorls of broken lines on anterior half; genital setae 31-41 long. Opisthosoma - first dorsal annulus twice as long (10-13) as each of subsequent annuli (5-6); annuli 2-11/13 elevated mesally, forming a conspicuous longitudinal ridge; annuli 7-14/16 with two lateral elevations forming two longitudinal ridges. Ventral annuli more numerous, with small, fine, elongate microtubercles. Lateral setae on annulus 3, 18-25 long. Ventral setae 1 on annuli 12-14, 54-63 long, 31-34 apart; ventral setae 2 on annuli 24-26, 8-10 long, 15-17 apart; ventral setae 3 on annuli 37-39 or 5th annulus from rear, 17-19 long, 17-19 apart. Total dorsal annuli 19-20, ventral 41-44. Caudal setae 63-75 long; accessory setae 2-3 long.

Male. Description from five specimens. Smaller than female, 122-137 long, 57-59 wide. Gnathosoma 24-25 long, basal setae 2 long; antapical setae 5-7 long; chelicerae 20-23 long; oral stylets 7-9 long. Prodorsal shield 34-46 long, 57-59 wide. Dorsal tubercles 19-24 apart, prodorsal setae 6-9 long. Legs I, 29-32 long; trochanters 2-3 long; femora 8-10 long; femoral setae 18-20 long; genua 4 long, genual setae 18-20 long; tibiae 6-7 long, tibial setae 4-5 long; tarsi 6-7 long, lateral setae 17-23 long, dorsal setae 13-20 long, mesal setae 2-3 long, solenidia 5-7 long, empodia 4-5 long, 4-rayed. Legs II, 25-31 long; trochanters 2-3 long; femora 8-10 long, femoral setae 8-10 long; genua 3-4 long, genual setae 4-5 long; tibiae 5-6 long; tarsi 5-6 long, lateral setae 17-19 long, dorsal setae 5 long, mesal setae 2-3 long; solenidia 5-6 long; empodia 5 long, 4-rayed. Coxae - setae 1, 5-7 long, 9-10 apart; setae 2, 11-13 long, 6-8 apart; setae 3, 32-36 long, 18-22 apart. Coxigenital region with 7-9 annuli, smooth. Epigynium 15-16 wide, 10-13 wide, punctuated; genital setae 29-31 long; with one pair of genital papillae, as figured. Opisthosoma -first dorsal annulus 10-11 long, twice as long as each of subsequent annuli (4-5 long). Lateral setae on annulus -3 , that is, on third incomplete annulus anterior to first complete ventral annulus. Ventral setae 1 on annuli 7-9 (from posterior end of genitalia), 40-48 long, 26-27 apart; ventral setae 2 on annuli 15-19, 6-10 long, 12 apart; ventral setae 3 on annuli 29-34 or 5th from rear, 16-18 long, 16-17 apart. Total dorsal annuli 19-21, ventral 33-38. Caudal setae 43-64 long; accessory setae 2 long.

Type female, 18 paratype females, six paratype males, on six microscopic preparations in the collection of Dept. Zoology, University of São Paulo, ESALQ (Piracicaba, São Paulo).

Type locality. Collected by the author on 27.XI.1970 and XII.1993, Campus "Luiz de Queiroz", University of São Paulo, Piracicaba (São Paulo, Brazil).

Host plant and relationship. Collected from lower leaf surface of Holocalyx glaziovii Taub. (Fabaceae), alecrim-de-Campinas. Mites were leaf vagrants.

Etymology. tricarinatus=three ridges, Latin, for the three longitudinal dorso-opisthosomal ridges. 


\section{Floracarus claviger, n.sp.}

Fig. 2

Diagnose. Floracarus claviger is the third species described from South America and the tenth species in the genus (other species are: 1 from Florida, USA and 6 from India). It is distinctive in having the prodorsal shield tubercles on rear shield margin and directing the setae backwards and divergent, as in F. calonyctionis Keifer, 1953 and in F. biharensis Das \& Chakrabarti, 1985 (in other known species of Floracarus the setae are inserted on the shield ahead of its rear margin) and in presenting the inarticulate knobbed tarsal II appendage, called "claw" and which is probably a sensory club (JEPPSON et al. 1975) long, at least one and half times as long as the featherclaw (empodium) - (about as long as empodium in the other species). Dorsal shield and epigynium designs peculiar, as figured.

Female. Description from five females, 143-172 long, 51-53 wide, fusiform. Gnathosoma directed downward, short, 18 long; basal setae 2 long; antapical setae 4 long; chelicerae 13 long. Prodorsal shield, including small frontal lobe, 16-32 long, 44-45 wide; design a network with granules and broken lines as figured; granules extending laterally to coxae. Dorsal tubercles on rear shield margin, 24-25 apart, directing setae backwards and slightly divergently, 15-17 long. Legs missing tibiae. Legs I, 23-26 long; trochanters 3 long; femora 8-10 long, femoral setae 8-10 long; genua 3 long, genual setae 18-21 long; tibiae absent; tarsi 7-9 long, lateral setae 15-19 long, dorsal setae 13-15 long, mesal setae 3-4 long, solenidia ("claw") 4-6 long, slightly knobbed, empodia 4-6 long, 4-rayed. Legs II, 20-22 long; trochanters 3 long; femora 8-10 long, femoral setae 8 long; genua 3 long, genual setae 10 long; tibiae missing; tarsi 5-7 long, lateral setae 18 long, dorsal setae 4 long, mesal setae 2 long, solenidia 8-9 long, empodia 4-6 long, 4-rayed. Coxae I fused, granular; setae 1 absent; no sternal line; setae 2, 9-10 apart, 12-16 long; coxae II with fewer granules, setae 3, 20 apart, 27-31 long. Coxigenital region with 3-4 annuli, microtuberculate. Epigynium 20 wide, 12-14 wide, with a mediolongitudinal line and 3 concentric semicircles of broken lines; genital setae 10 long. Opisthosoma evenly arched, circular in transversal section. Lateral setae 23-28 long, on annuli 4-5; ventral setae 1, 49-51 long, 35 apart, on annuli 12-14; ventral setae 2, 10-12 long, 18-22 apart, on annuli 25-30; ventral setae 3, 17-20 long, 13-15 apart, on annuli 42-47 or 6-7th annuli from rear. Total dorsal annuli 52-62, ventral 51-60. Caudal setae 37-49 long; accessory setae, when present, 1 long.

Male. Description from five specimens, smaller then female, 130-145 long, 48-52 wide. Gnathosoma 18 long, basal setae 1-2 long; antapical setae 4-5 long; chelicerae 12 long. Prodorsal shield 24-31 long, 42-48 wide; tubercles 23-24 apart, setae 14-17 long. Legs - tibiae missing. Legs I, 22-24 long; femora 9-11 long, femoral setae 9-11 long; genua 3 long, genual setae 19-21 long; tibiae absent; tarsi 6-7 long, lateral setae 14-18 long, dorsal setae 12-14 long, mesal setae 2 long, solenidia 5-7 long, empodia 5-6 long, 4-rayed. Legs II, 20-22 long; femora 10 long, femoral setae 7-9 long; genua 3 long, genual setae 10 long; tibiae absent; tarsi 7 long, lateral setae 17-22 long, dorsal setae 4-5 long, mesal setae 2-3 long, solenidia 8 long, empodia 5 long, 4-rayed. Coxae - setae 1 absent; setae 2, 11-14 long, 7-9 


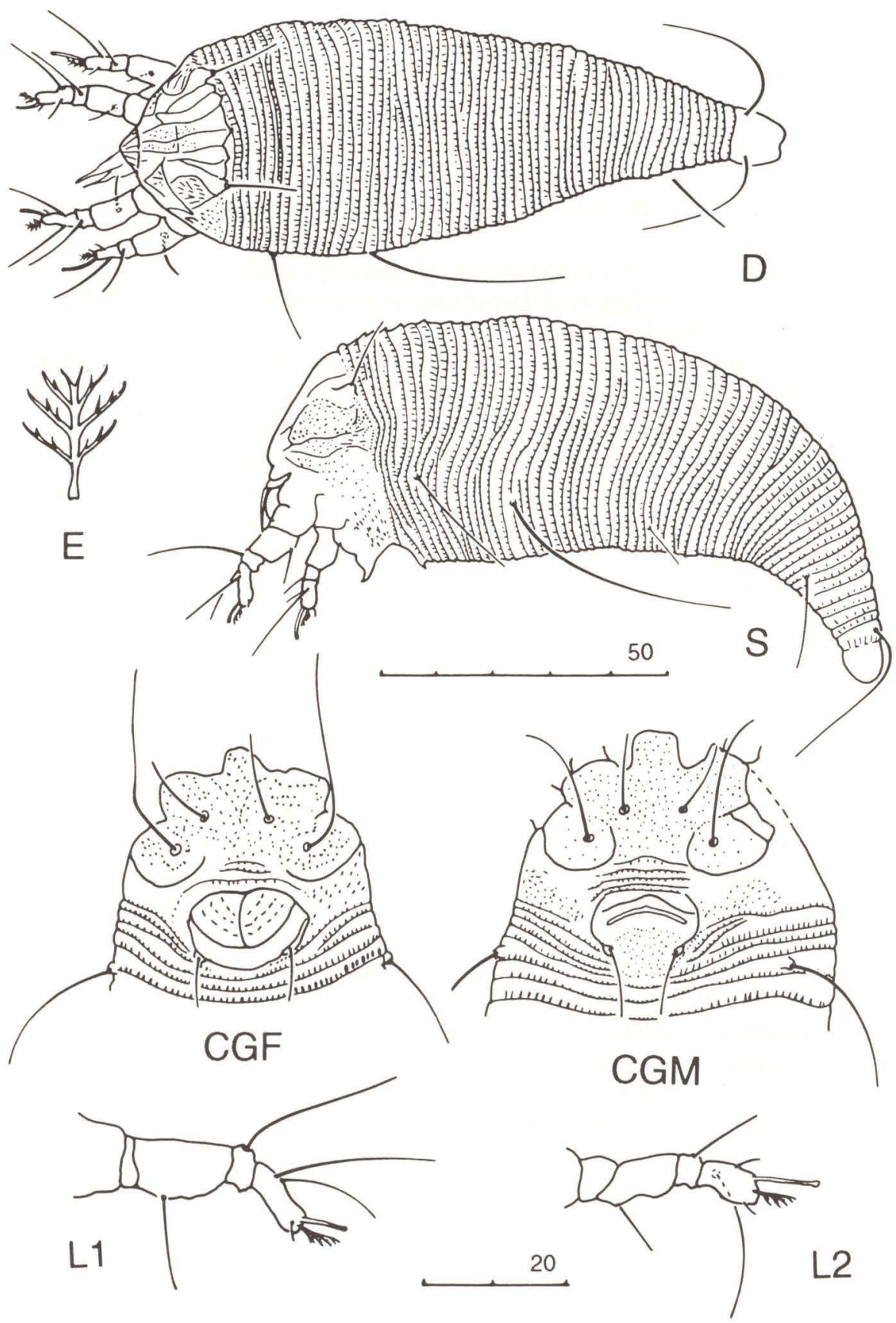

Fig. 2. Floracarus claviger, n.sp. CGF, D, E, L1, L2 - female; CGM - male. (CGF) Coxigenital region; (D) dorsal aspect; (E) empodium; (L1) leg I; (L2) leg II; (CGM) coxigenital region. 
apart; setae 3, 24-26 long, 17 apart. Coxigenital region with 3-5 annuli, microtuberculate. Genitalia 15 wide, 12-13 wide, with granules. Genital setae 7-10 long. Opisthosoma - lateral setae 24-29 long, on annuli 1-3; ventral setae 1, 43-46 long, 32-34 apart, on annuli 9-13; ventral setae 2, 10-14 long, 18 apart, on annuli 20-26; ventral setae 3, 18-22 long, 15 apart, on annuli 31-46 or 6-7h annuli from rear. Total dorsal annuli 52-58; ventral 37-52. Caudal setae 38-46 long; accessory setae, when present, 1 long.

Type female, 26 paratype females, eight paratype males, on five microscopic preparations in the collection of Department of Zoology, University of S. Paulo, ESALQ (Piracicaba, São Paulo).

Type locality. Collected by the author, 30.XII.1993, Parque Nacional do Itatiaia (Rio de Janeiro, Brasil).

Host plant and relationship - collected from the lower leaf surface of Cordia sp., Boraginaceae; mites were leaf vagrants; no apparent symptoms of damage.

Etymology. claviger, Latin masculine, meaning club bearing, referring to the large "claws" (solenidia) on tarsus II.

Observation Floracarus is compounded from the first part of Florida, plus acarus (KEIFER 1953). Since acarus, NeoLatin masculine, is the governing noun, Floracarus is masculine.

\section{Cosella callipodex, n.sp.}

Fig. 3

Diagnose. Cosella callipodex is distinctive in presenting three ventral opisthosomal semicircular plateletlike structures, caudad of the last annulus, not present in any of the 4 known species; dorsal shield setae are directed backwards as in C. cissi Keifer, 1978 (in C. ischnocarpasia Mondal \& Chakrabarti, 1981 dorsal shield setae are directed laterad, in C. simplicis Manson, 1984 posteromedially and in $C$. deleoni (KEIFER 1956) lateroposteriorly at an $45^{\circ}$ angle). The structure of the lateral and ventral body setae of C. callipodex is also peculiar: the basal one fifth of their extension has a smaller diameter than the next one fifth and from there on they taper uniformly toward their tip.

Female. Description from five specimens. Body fusiform, tapering posteriorly, 137-193 long, 60-66 wide, Gnathosoma directed downward, 16-17 long; basal setae 3 long; antapical seta 2-3 long; chelicerae 10-11 long; oral stylets 5 long. Prodorsal shield 33-40 long, 54-60 wide; design a network as figured, with lateral granules extending down to coxae. Dorsal tubercles ahed of rear shield margin, 28-31 apart, directing setae backwards, these 9-11 long. Legs missing tibiae. Legs I, from trochanter base, 22-25 long; trochanters 3 long; femora 9 long, distal half granulated, femoral setae 7-9 long; genua 3 long, genual setae 25-33 long; tibia absent; tarsi 6-10 long, lateral setae 18-24 long, dorsal setae 12-18 long, mesal setae 3-4 long, solenidia 4 long, slightly knobbed, empodia 4-5 long, 4-rayed. Legs II, 21-22 long; trochanters 3 long; femora 9 long, distal half granulated, femural setae 9 long; genua 2-3 long, genual setae 8-10 long; tibiae absent; tarsi 7 long, lateral

Revta bras. Zool. 13 (1): 109 - 119, 1996 

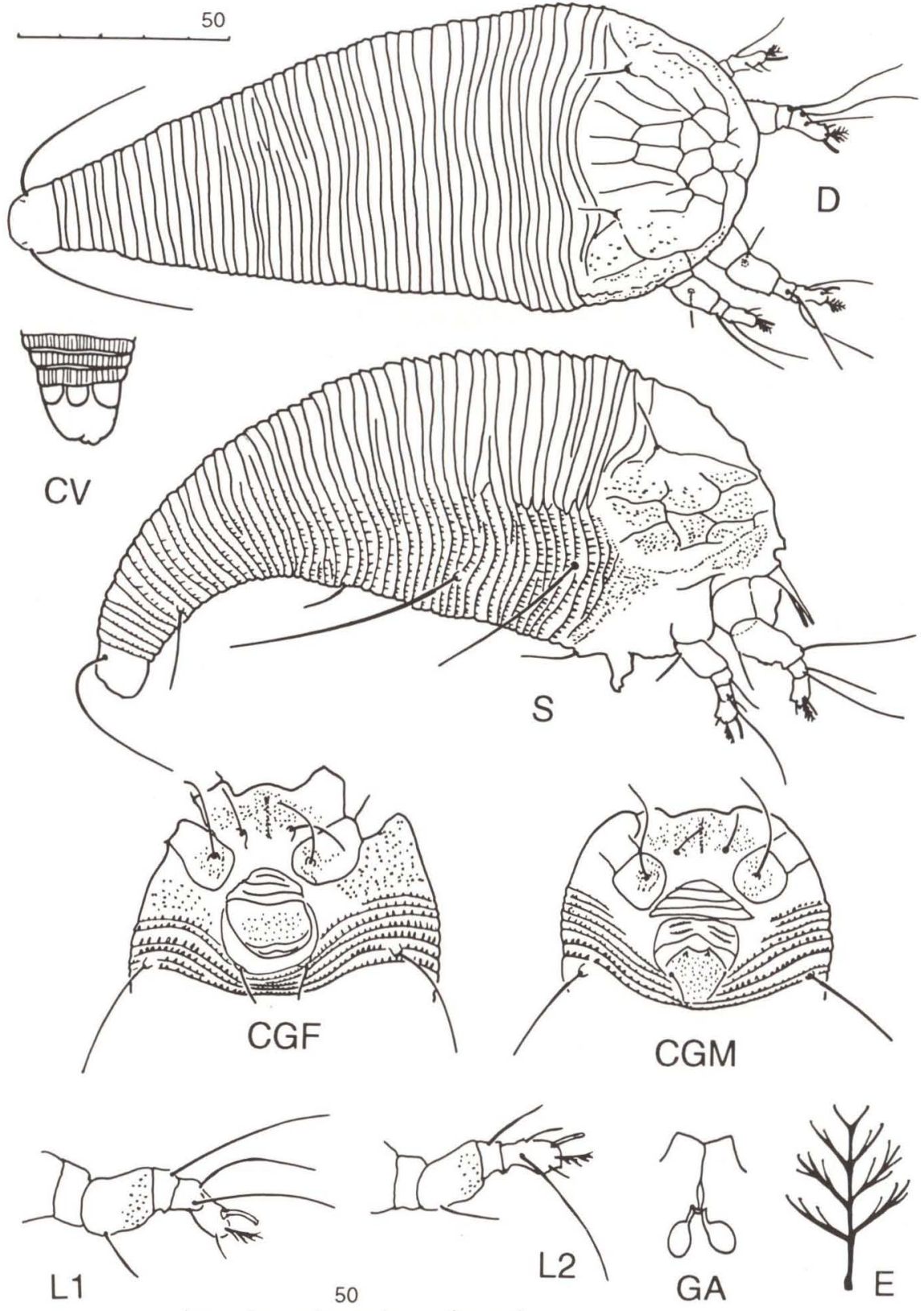

Fig. 3. Cosella callipodex, n.sp. CGF, CV, D, E, GA, L1, L2, S - female; CGM - male. (CGF) Coxigenital region; (CV) caudoventral aspect; (D) dorsal aspect; (GA) genital apodeme; (L1) leg I; (L2) leg II: (S) lateral aspect; (CGM) coxigenital region. 
setae 14-23 long, dorsal setae 4 long, mesal setae 3 long, solenidia 4 long, knobbed, empodia 5 long, 4-rayed. Coxae I fused, granulate, apodemes underneath, slightly visible, first coxal tubercle and setae absent; setae 2, 10-11 apart, 9-13 long; coxae II with a few granules around bases of setae 3, which are 17-20 apart, 29-35 long. Coxigenital region without discernible annuli in some specimens, with 3 annuli in other. Epigynium 19-22 wide, 13-17 long, granulate and 2 transverse scorings posteriorly; genital setae 6-8 long. Opisthosoma with all setae presenting the proximal one fifth smaller in diameter than the next one fifth and from there on gradually tapering. Lateral setae 20-33 long, on annuli 2-3; ventral setae 1, 49-58 long, 34-35 apart, on annuli 13-14; ventral setae 2, 8-10 long, 16-17 apart, on annuli 24-27; ventral setae 3, 16-17 long, 17 apart, on annuli 44-47 or 6-7th from rear. Total dorsal annuli 47-53, without microtubercles; total ventral annuli 50-53, with narrow, elongate microtubercles, not evenly distributed along the sternites. Caudad of last ventral annulus (or sternite) 3 semicircular plateletlike structures. Caudal setae 32-50 long; accessory setae less than 1 long.

Male. Description from five specimens. Smaller than female, 143-154 long, 57-59 wide. Gnathosoma 16-17 long, basal setae 3-4 long, antapical setae 3-4 long, chelicerae 9-11 long, oral stylets 7-8 long. Prodorsal shield 29-32 long, 54-56 wide, dorsal tubercles 27-28 apart, setae 7-9 long. Legs missing tibiae. Legs I, 22-23 long; trochanters 3 long; femora 9 long, femoral setae 7-8 long; genua 3 long, genual setae 17-24 long; tibiae absent; tarsi 7 long, lateral setae 17-24 long, dorsal setae 13-14 long, mesal setae 3-4 long, solenidia 5 long, knobbed, empodia 5 long, 4-rayed. Legs II, 20-21 long; trochanters 3 long; femora 9 long, femoral setae 9 long; genua 3 long, genual setae 9-11 long; tibiae absent; tarsi 6-7 long, lateral setae 18 long, dorsal setae 4 long, mesal setae 3 long, solenidia 4 long, knobbed, empodia 5 long, 4-rayed. Coxae I fused, granulate; setae 1 absent; setae 2, 9-11 apart, 10-12 long; coxae II partially granulate, setae 3, 19-21 apart, 23-30 long. Coxigenital region with 3-4 anterior annuli without microtubercles and 2 posterior annuli micro-tuberculate and mesally interrupted. Epigynium 17 wide, 11 long, granulate, with 2 angular, anterior and approximate papillae; genital setae 6 long. Opisthosoma -lateral setae 26-28 long, on annuli 3-5; ventral setae 1,31 apart, 42-46 long, on annuli 11-14; ventral setae 2, 15 apart, 8-10 long, on annuli 20-25; ventral setae 3, 16 apart, 17-18 long, on annuli 38-44. Total dorsal annuli 46-51, without micro-tubercles; total ventral annuli 44-50, microtuberculate. Caudal setae 31-42 long; accessory setae, when present, less than 1 long.

Type female, 46 paratype females, nine paratype males on one microscopic preparation in the collection of Department of Zoology, University of São Paulo, ESALQ (Piracicaba, São Paulo).

Type locality. Collected by the author, on 14.II.1994, Parque Nacional do Itatiaia (Rio de Janeiro, Brazil).

Host plant and relationship. Collected from the lower leaf surface of Croton lundianus M. Arg., Euphorbiaceae. Mites were leaf vagrants; the infested leaves showed bronzing.

Etymology. The specific designation, callipodex, is a composite of calli, from the Greek callos, meaning beauty, ornated, plus podex, Latin, meaning rump, 
fundament, anus. That is, with an ornated ventral opisthosoma, referring to the presence of three ventral semicircular platelike structures caudad of the last ventral annulus and near the anus.

NEWKIRK \& KEIFER (1975) composed Cosella of co, meaning together, and sella, referring to the coxae. Since sella is Latin feminine, the genus Cosella is feminine.

\section{Aculus verrucosus, n.sp.}

Fig. 4

Diagnosis. Aculus verrucosus is characterized by dorsal shield design of prominent granulations or tubercles, part of them arranged in two oval patterns; resembles A. malivagrans (Keifer, 1946) and A. broussaisiae Keifer, 1964, the only other members of Aculus with such ornamentation; in the former the tubercles are arranged in curved longitudinal lines plus some sparsed ones, and, in the latter they are scattered. In $A$, verrucosus the dorsal annuli or tergites are smooth while in the other two species mentioned they are microtuberculate.

Female. Description from six specimens, body elongate 164-176 long, 68-74 wide. Gnathosoma 25 long, basal setae 3 long, antapical setae 4-5 long; chelicerae 11-15 long; oral stylets 8-10 long. Prodorsal shield 28-33 long, 58-63 wide, with prominent granulations, part of them arranged in 2 oval patterns. Prodorsal tubercles subcylindrical, on rear shield margin, 26-28 apart, directing setae caudad. Prodorsal setae 8-10 long. Legs - all segments and setae present. Legs I, 29-32 long; trochanters 5-6 long; femora 10 long, with one distal dorsal spine, femoral setae 9 long; genua 5 long, genual setae 19-20 long; tibiae 3-4 long, with one distal dorsal spine, tibial setae in lateral-mesal position, 3-4 long; tarsi 5-6 long, with lateral setae 19-23 long, dorsal setae 15-18 long, mesal setae 5 long, tarsal solenidia 7 long, empodia 6 long, 5-rayed. Legs II, 28-32 long; trochanters 4-6 long; femora 10-11 long, with a minute dorsal distal spine, femoral setae 8-9 long; genua 4 long, genual setae 5 long; tibiae 6 long with two distal spines, one dorsal and one ventral; tarsi 6 long, with lateral setae 17-21 long, dorsal setae 4-5 long, mesal setae 4 long, tarsal solenidia 7 long, empodia 6 long, 5-rayed. Coxal setae 1, 6-9 long, 12-13 apart; coxal setae 2, 10-13 long, 9 apart; coxal setae 3, 25-39 long, 22-25 apart. Sternal line 6-7 long. Coxigenital region with 8-10 annuli, microtuberculate. Genital coverflap 21-22 wide, 10-13 long, with about 14 longitudinal lines; genital setae 5-7 long. Opisthosoma - dorsal annuli evenly arched, without microtubercles. Ventral annuli microtuberculate. Lateral setae 10 long, on annuli 5-7; ventral setae 1, 36-40 long, 36-38 apart, on annuli 15-22; ventral setae 2, 6-8 long, 18-22 apart, on annuli 30-38; ventral setae 3, 14-17 long, 18-22 apart, on annuli 48-56 or 4-5th from rear. Total dorsal annuli 25-28, ventral annuli 49-60. Caudal setae 41-46 long, accessory setae 3 long.

Male. Not seen.

Type female, 22 paratype females, on three microscopic preparations in the collection of Department of Zoology, University of São Paulo, ESALQ (Piracicaba, São Paulo). 

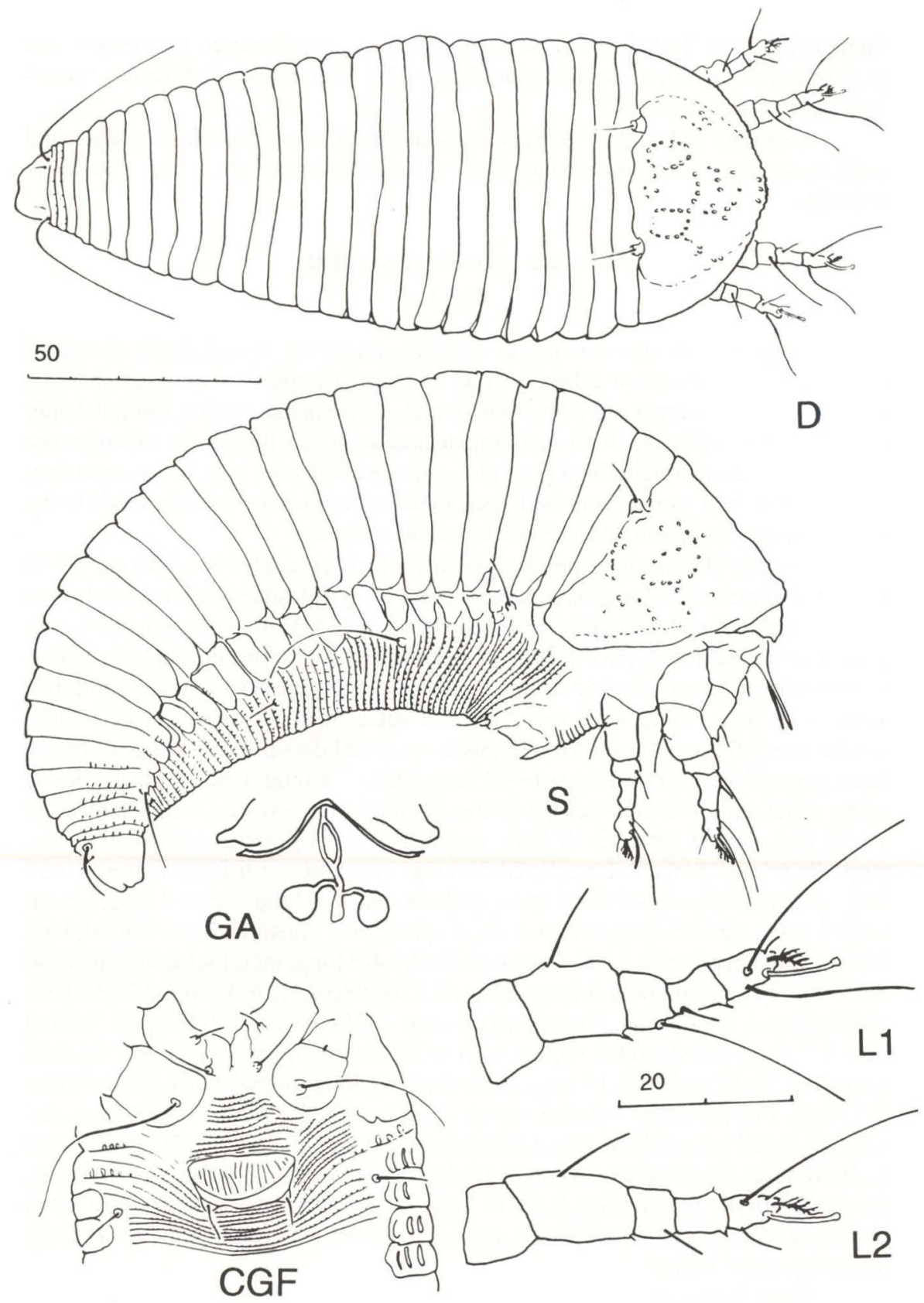

Fig. 4. Aculus verrucosus, n.sp. female. (CGF) Coxigenital region; (D) dorsal aspect; (GA) genital apodeme; (L1) leg I; (L2) leg II; (S) lateral aspect. 
Type locality. Collected by the author on 14.II.1994, from Parque Nacional do Itatiaia, Rio de Janeiro, Brazil.

Host plant and relationship. From the lower leaf surface of Croton lundianus M. Arg., Euphorbiaceae; mites were leaf vagrants and infested leaves showed bronzing or rust.

Etymology. verrucosus, Latin, meaning full of warts, referring to the dorsal shield ornamentation.

Aculus is derived from Acarus, Neo Latin masculine, plus the diminutive ulus (KEIFER 1959). Since Latin diminutives have the same gender as parent nouns (BRown 1979) Aculus is masculine.

Observation. Cosella callipodex and Aculus verrucosus are sympatric and synechotonous. $A$. verrucosus may be the deutogyne of $C$. callipodex.

\section{REFERENCES}

BRown, R.W. 1979. Composition of Scientific Words. Washington, Smithsonian Inst. Press, $882 \mathrm{p}$.

Das, A.K. \& S. Chakrabarti. 1985. Studies on Eriophyid mites (Acarina: Eriophyoidea) of India. XVI. One new genus and ten new species from India. Oriental Insects 19: 133-153.

JEPPSON, L.R.; H.H. KEIFER \& E.W. BAKER. 1975. Mites Injurious to Economic Plants. Univ. Calif. Press, XXIV+614p.

KeIfer, H.H. 1939. Eriophyid Studies. IV. Bull. Calif. Dept. Agric. 28 (3): 223-239.

1946. Eriophyid Studies. XVI. Bull. Calif. Dept. Agric. 35 (1): 39-48.

1953. Eriophyid Studies. XXI. Bull. Calif. Dept. Agric. 42 (2): 65-79.

1955. Eriophyid Studies. XXIV. Bull. Calif. Dept. Agric. 44 (4): 159-164.

1959. Eriophyid Studies XXVII. Bur. Entomol. Calif. Dept. Agric. Occas. Pap. (1): 1-18.

1964. Eriophyid Studies. B-12. Bur. Entomol. Calif. Dept. Agric., 20p. 1978. Eriophyid Studies. C-15. Agric. Res. Serv., USDA, 18p.

MANSON, D.C.M. 1984. Eriophyoidea except Eriophyinae (Arachnida: Acari). Fauna of New Zealand, Wellington, (4): 1-142.

Mondal, S. \& C. Chakrabarti. 1981. Studies on Eriophyid mites (Acarina: Eriophyoidea) of India. X. New genus and new species from West Bengal. Oriental Insects 15 (3): 313-319.

NEWKIRK, R.A. \& H.H. KEIFER. 1975. Eriophyoidea: synoptic keys to groups and genera, p.562-587. In: L.R. JEPPSON; H.H. KEIFER \& E.W. BAKER (Eds). Mites Injurious to Economic Plants. Univ. Calif. Press, 614p.

Roivainen, H. 1950. Eriophyid news from Sweden. Acta. Entomol. Fenn. 7: 1-51. 